Vol. 10 No. 1, Januari 2020

p-ISSN: 2087-7897 ; e-ISSN : 2460-5344

DOI : $10.30700 /$ jst.v10i1.747

\title{
Sistem Pakar Deteksi Dini Kesehatan Mental Menggunakan Metode Dempster-Shafer
}

\section{Mental Health Initial Detection Expert System Using Dempster Shafer Method}

\author{
Annisa Rahmadhani*1, Fauziah $^{2}$, Andri Aningsih ${ }^{3}$ \\ 1,2,3 Universitas Nasional; Jl. Sawo Manila, Telp: (021) 7806700 \\ 1,2,3 Jurusan Sistem Informasi, FTKI UNAS, Jakarta \\ e-mail: *11 rahmadhaniannisa44@gmail.com, 2fauziah@ civitas.unas.ac.id, \\ 3andrianingsih@civitas.unas.ac.id
}

\begin{abstract}
Abstrak
Kesehatan mental merupakan aspek penting yang juga harus diperhatikan sebagaimana kesehatan fisik. Kurangnya kesadaran publik akan kesehatan mental serta keterbatasan waktu dan biaya menjadi beberapa kendala seseorang untuk enggan untuk memeriksakan dirinya pada psikolog/pakar. Penelitian ini bertujuan untuk meningkatkan kesadaran masyarakat akan pentingnya kesehatan mental dan mendeteksi dini apakah seseorang memiliki kecenderungan untuk mengalami masalah pada kesehatan mentalnya dengan sistem pakar menggunakan metode dempster-shafer yang merupakan metode berdasarkan teori fungsi keyakinan dengan menggunakan variabel belief (keyakinan) dan variabel plausibility. Hasil dari penelitian ini adalah sebuah sistem pakar berbasis web yang dapat mendeteksi apakah seseorang memiliki kecenderungan masalah pada kesehatan mentalnya berdasarkan kondisi yang dialami oleh pengguna dan memberikan informasi terkait dengan kesehatan mental. Pengujian akurasi sistem perbandingan antara hasil sistem dan hasil pakar dengan menggunakan 100 data uji mendapatkan persentase 94\% dan pengujian usability sistem berdasarkan 31 koresponden mendapatkan nilai 3.95 dari total nilai 5. Diharapkan pada penelitian selanjutnya dapat dikembangkan dengan mengintegrasikan sistem kepada psikolog di lokasi sekitar pengguna untuk konsultasi sehingga memudahkan pengguna dalam penanganan lanjut serta memberikan solusi yang lebih rinci terkait masalah pada kesehatan mental. Selain itu, diharapkan sistem dapat dikembangkan dari platform dari web menjadi berbasis android/ios agar memudahkan pengguna untuk mengakses sistem.
\end{abstract}

Kata kunci-Sistem Pakar, Kesehatan Mental, Dempster Shafer. Deteksi Dini, Berbasis Web

\begin{abstract}
Mental health is an important aspect that needs attention as much as physical health. Lack of public awareness of mental health and the deficiency time and money become some of the thought for someone to be reluctant to check himself with a psychologist / expert. This study aims to do an initial detection by detecting whether a person has a tendency to experience problems in his mental health with an expert system using the dempster-shafer method which is a method based on the theory of belief functions using the belief variable (belief) and plausibility variable.
\end{abstract}


The results of this study are a web-based expert system that can detect whether a person has a tendency for mental health problems based on the conditions experienced by the user and provide information related to mental health. Testing the accuracy of the system comparation between system result and expert result used 100 data and get $94 \%$ percentage and system usability testing based on 31 correspondents and get score 3.95 out of 5. We hope that further research can develop the system by integrating the system with psychologists in around the user's locations to consult so it is easier for users to provide more detailed solutions related to problems in mental health. In addition, it is expected that the system can be developed from the web platform to be based on Android / iOS that it will be easier for users to access the system.

Keywords - Expert System, Mental Health, Dempster-Shafer, Initial Detection, Web Based

\section{PENDAHULUAN}

Kesehatan mental merupakan aspek penting yang perlu diperhatikan sebagaimana kesehatan fisik. Seringkali kesehatan mental diabaikan oleh kebanyakan masyarakat karena berbeda dengan kesehatan fisik yang kasat mata dan dapat diidentifikasi dengan mudah[1]. Berdasarkan World Health Organization (WHO), kesehatan mental adalah keadaan dimana individu menyadari kemampuannya sendiri, dapat mengatasi tekanan hidup yang normal, dapat bekerja secara produktif dan subur, dan mampu memberikan kontribusi ke lingkungan sekitarnya. Berdasarkan hasil riskesdas (riset kesehatan dasar kementrian kesehatan) tahun 2018, terdapat kenaikan sebanyak 3,8\% penduduk berumur > 15 tahun yang mengalami gangguan mental emosional di Indonesia. Kenaikan ini dapat dikatakan sebagai tanda bahwa selayaknya masyarakat harus meningkatkan kesadaran terhadap kesehatan mental. Karena kurangnya kesadaran akan kesehatan mental dalam kehidupan masyarakat Indonesia dan anggapan bahwa seseorang yang pergi ke psikolog merupakan seseorang yang kurang waras, seringkali individu yang sebenarnya mengalami masalah kesehatan mental enggan untuk mendapatkan pertolongan dari ahli atau menyangkal bahwa dirinya tidak memiliki masalah kesehatan mental. Keterbatasan waktu dan biaya juga menjadi salah satu kendala seseorang enggan untuk mendapatkan pertolongan dari ahli seperti psikolog. Oleh karena itu, sistem pakar berbasis web dibangun untuk digunakan sebagai deteksi dini dan memungkinkan pengguna untuk mengetahui apakah pengguna tersebut memiliki kecenderungan masalah pada kesehatan mentalnya atau tidak sebelum dibutuhkan konsultasi resmi dari ahli.

Pada penelitian sebelumnya membahas tentang sistem pakar untuk mendeteksi gangguan mental anak menggunakan metode Dempster-Shafer berbasis web yang menggunakan 40 data uji perbandingan antara hasil diagnosa sistem dan hasil diagnosa pakar dan menghasilkan tingkat akurasi sebesar 95\%[2]. Penelitian lain penerapan metode Dempster-Shafer menggunakan 20 data uji perbandingan antara hasil diagnosa sistem dan hasil diagnosa pakar dan menghasilkan tingkat akurasi sebesar $85 \%$ [3]. Penelitian selanjutnya menggunakan 10 data uji perbandingan antara hasil diagnosa sistem dan hasil diagnosa pakar dan menghasilkan tingkat akurasi sebesar 80\%[4]. Penelitian lain menggunakan 104 data uji antara hasil diagnosa sistem dan hasil diagnosa pakar dan menghasilkan tingkat sebanyak 94,23\%[5]. Penelitian selanjutnya menggunakan 60 data uji perbandingan antara hasil diagnosa sistem dan hasil diagnosa pakar dan menghasilkan presentase keberhasilan sebanyak $88,33 \%[6]$. Penelitian selanjutnya merupakan penelitian perbandingan antara metode Dempster-Shafer dan metode Certainty Factor yang menghasilkan perbandingan nilai akurasi $90 \%$ pada metode dempster shafer yang didapatkan dari hasil diagnosa sistem pakar sedangkan nilai akurasi $85 \%$ pada metode certainty factor yang didapatkan dari hasil diagnosa sistem pakar [7]. Penelitian terakhir yang merupakan penelitian perbandingan antara metode Dempster-Shafer dan metode Certainty Factor yang menghasilkan nilai akurasi 85\% pada metode 
dempster shafer yang didapatkan dari hasil diagnosa sistem pakar sedangkan nilai akurasi $80 \%$ pada metode certainty factor yang didapatkan dari hasil diagnosa sistem pakar [8].

Penelitian ini menggunakan metode dempster shafer karena berdasarkan tinjauan pustaka yang dilakukan dengan membandingkan metode dempster-shafer dengan metode yang lain, metode dempster-shafer dinilai lebih akurat dalam mendiagnosa penyakit berdasarkan gejalagejalanya berdasarkan nilai belief dari pakar. Dalam penelitian ini, aplikasi sistem pakar deteksi dini kesehatan mental dibuat dengan fitur login user, konsultasi, hasil konsultasi, informasi terkait kesehatan mental, dan histori terkait konsultasi yang telah dilakukan.

Agar masalah yang dibahas tidak menyimpang dari judul, sehingga penulis membatasi masalah yang akan dibahas seperti metode Dempster-Shafer diterapkan untuk merekomendasikan apakah seseorang terindikasi memiliki masalah pada kesehatan mental atau tidak, instrumen kesehatan mental yang dipilih user hanya kondisi yang dirasakan user selama 30 hari terakhir, dan perancangan program aplikasi sistem pakar ini menggunakan database management system MySQL dan Bahasa pemrograman PHP.

Tujuan dari penelitian ini adalah untuk merancang aplikasi sistem pakar berbasis web untuk merekomendasi apakah seseorang memiliki kecenderungan mempunyai masalah pada kesehatan mentalnya, informasi terkait dengan kesehatan mental serta meningkatkan kesadaran akan kemungkinan masalah pada kesehatan mental yang sebenarnya dialami pada diri individu namun tidak pernah disadari serta sistem ini dapat menghemat waktu dan biaya dan melakukan pengujian akurasi perbandingan antara hasil sistem dan hasil pakar serta pengujain usability pada sistem. Hasil dari penelitian ini diharapkan sistem ini dapat membantu masyarakat untuk merekomendasi kemungkinan apakah seseorang memiliki kecenderungan masalah pada kesehatan mentalnya, informasi terkait bagaimana menjaga kesehatan mental, dan pengujian akurasi perbandingan antara hasil sistem dan hasil pakar serta pengujain usability pada sistem.

\section{METODE PENELITIAN}

\subsection{Alur Penelitian}

Tahapan awal dalam penelitian ini adalah merumuskan masalah deteksi dini kesehatan mental yang ingin kita selesaikan dengan sistem pakar. Selanjutnya adalah mengumpulkan sumber bacaan dari berbagai jurnal, buku, dan sumber lain yang berkaitan dengan penelitian ini.. Setelah tinjauan pustaka, dilakukan pengumpulan data untuk menunjang fakta-fakta yang akan digunakan sebagai informasi dalam sistem ini dengan melakukan observasi dan wawancara pada pakar. Lalu tahap perancangan sistem yaitu meliputi perancangan desain arsitektur sistem, perancangan, basis data, antar muka, dan pengujian sistem . Setelah dirancang, sistem akan dibuat berdasarkan peracangan yang sudah dibuat. Selanjutnya, pengujian dilakukan untuk mengetahui kelayakan sistem. Ketika dalam pengujian, jika hasil tingkat keakuratannya tidak sesuai dengan harapan maka akan dilakukan analisa kembali pada perancangan sistem. Jika pengujian berhasil, kesimpulan akan diambil. Berikut gambar alur penelitian yang meliputi beberapa langkah:

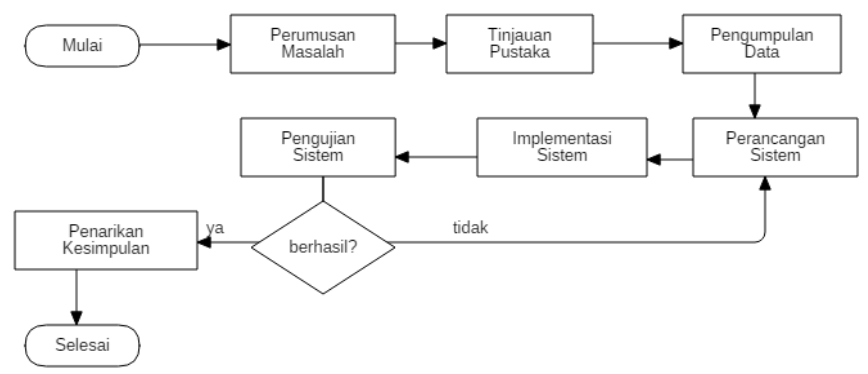

Gambar 1. Alur Penelitian 


\section{2 Dempster Shafer}

Teori dempster-shafer adalah suatu teori matematika untuk pembuktian berdasarkan belief functions (fungsi kepercayaan) dan plausible reasoning (pemikiran yang masuk akal), yang digunakan untuk mengkombinasikan potongan informasi yang terpisah (bukti) untuk mengkalkulasi kemungkinan dari suatu peristiwa [2]. Secara umum teori Dempster-Shafer ditulis dalam suatu interval:

\section{[Belief, Plausibility]}

Belief (Bel) merupakan ukuran kepercayaan evidence untuk mendukung suatu himpunan. Nilai Belief diberikan oleh pakar berdasarkan ilmu pengetahuan pakar terhadap jenis evidence. Nilai Bel ini berada dalam kisaran [0...1], Jika nilai $\mathrm{Bel}=0$ artinya tidak ada evidence dan $\mathrm{Bel}=$ 1 artinya kepastian. Fungsi belief dapat diformulasikan dan ditunjukkan pada persamaan (1) [2]. $\operatorname{Bel}(X)=\sum_{Y \subseteq X} m(Y)$

Plausibility (Plau) juga bernilai 0 sampai 1, jika kita yakin terhadap X, maka dapat dikatakan bahwa $\operatorname{Bel}(X)=1$, dan $\operatorname{Pls}(X)=0$. Plausibility mengurangi tingkat kepercayaan dari evidence. Plausibility (Pls) dinotasikan pada persamaan (2).

$\operatorname{Pls}(X)=1-\operatorname{Bel}(X)=1-\sum_{Y \subseteq X} m(Y)$

dimana:

$\operatorname{Bel}(X)=\operatorname{Belief}(X)$

$\operatorname{Pls}(X)=$ Plausibility $(X)$.

$m(Y)=$ mass function .

Pada teori Dempster-Shafer adanya frame of discernment yang dinotasikan dengan $\theta$ dan mass function yang dinotasikan dengan $\mathrm{m}$. frame of discernment adalah semesta pembicaraan dari sekumpulan hipotesis sehingga sering disebut dengan environment. Sedangkan mass function (m) dalam teori Dempster-Shafer adalah tingkat kepercayaan dari suatu evidence (instrumen kesehatan mental), sering disebut dengan evidence measure sehingga dinotasikan dengan $(\mathrm{m})$. Pada sistem ini, terdapat sejumlah evidence (instrumen kesehatan mental) yang akan digunakan psada faktor ketidakpastian dalam menentikan hasil deteksi dini. Untuk mengatasi sejumlah evidence tersebut pada teori Dempster-Shafer menggunakan aturan yang lebih dikenal dengan Dempster's Rule of Combination pada persamaan (3) [2].

$m_{z}(Z)=\frac{\sum X \cap Y=Z m_{x}(X) \cdot m_{y}(Y)}{1-K}$

Dimana :

$m_{z}(Z)=$ mass function dari evidence $\mathrm{z}$.

$m_{x}(X)=$ mass function dari evidence $\mathrm{x}$.

$m_{y}(Y)=$ mass function dari evidence $\mathrm{y}$.

$\sum_{X \cap Y=Z} m_{x}(X) \cdot m_{y}(Y)=$ jumlah dari irisan pada perkalian $\mathrm{m}_{\mathrm{x}}$ dan $\mathrm{m}_{\mathrm{y}}$

$K=$ perkalian dari mass function yang mengalami konflik evidence bila irisannya kosong.

Berikut penjelasan alur metode dempster-shafer yang dapat dilihat pada gambar 2 . 


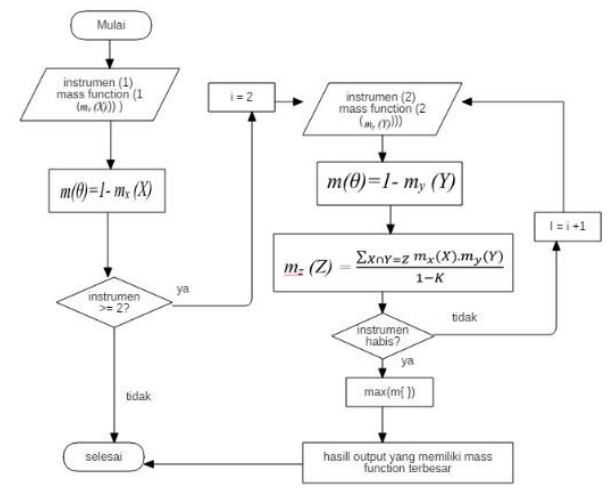

Gambar 2 Alur Metode Dempster-Shafer

Keterangan

$\mathrm{i}=$ instrumen (evidence).

$\mathrm{m}=$ nilai mass function / kepercayaan.

$\mathrm{X}$ dan $\mathrm{Y}=$ output.

$\mathrm{I}=$ iterasi

\subsection{Perancangan Sistem}

\subsubsection{Usecase Diagram}

Pada gambar 3, usecase diagram menggambarkan bahwa admin mendapatkan hak akses penuh pada sistem seperti dapat mengakses instrumen, menghapus dan mencetak laporan, serta menghapus user. Sedangkan pada user hanya dapat hak akses untuk mengakses konsultasi dan histori konsultasi.

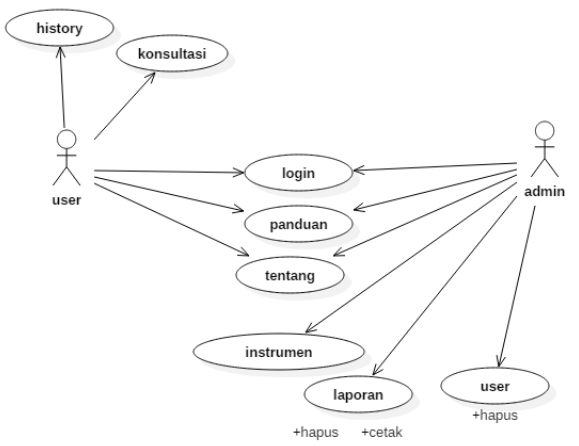

Gambar 3 Usecase Diagram

\subsubsection{Activity Diagram}

Pada gambar 4 adalah activity diagram dari sistem pakar deteksi dini kesehatan mental yang merupakan gambaran diagram alur aktivitas antar user dan sistem dari sistem pakar yang digunakan agar user dapat mengetahui dengan mudah bagaimana alur dari sistem tersebut. 


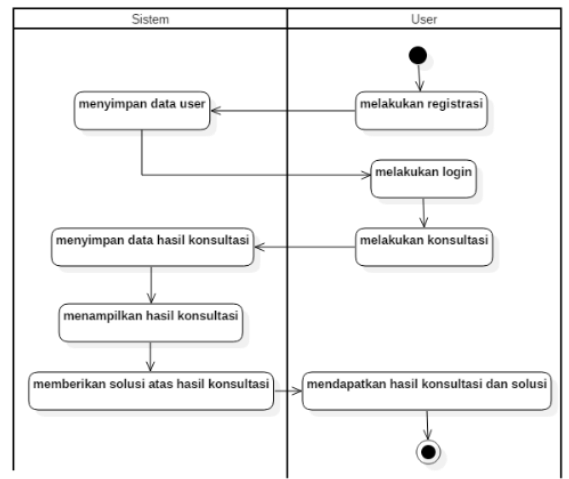

Gambar 4 Activity Diagram

\section{HASIL DAN PEMBAHASAN}

\subsection{Basis Pengetahuan}

Basis pengetahuan merupakan komponen yang berisi pengetahuan yang berasal dari pakar, berisi sekumpulan fakta dan aturan[6]. Berikut merupakan pembentukan aturan output, instrumen kesehatan mental, dan nilai belief yang didapat dari hasil wawancara bersama psikolog berdasarkan persentase kemungkinan seseorang mengalami masalah kesehatan mental dalam setiap instrumen.

Tabel 1 Output Indikasi Kesehatan mental

\begin{tabular}{cc}
\hline Kode Output & Nama Output \\
\hline O1 & Terindikasi Memiliki Masalah Pada Kesehatan Mental \\
\hline O2 & Tidak Terindikasi Memiliki Masalah Pada Kesehatan Mental \\
\hline
\end{tabular}

Tabel 2 Instrumen dan Nilai Belief Kesehatan Mental

\begin{tabular}{|c|c|c|}
\hline Kode & Instrumen & Belief \\
\hline I1 & Sering Menderita Sakit Kepala & 0.8 \\
\hline $\mathrm{I} 2$ & Tidak Memiliki Nafsu Makan & 0.8 \\
\hline $\mathrm{I} 3$ & Sulit Tidur & 0.7 \\
\hline I4 & Mudah Takut & 0.5 \\
\hline I5 & Merasa Tegang, Cemas, Atau Kuatir & 0.6 \\
\hline I6 & Tangan Mudah Gemetar & 0.4 \\
\hline I7 & Pencernaan Terganggu/Buruk & 0.7 \\
\hline I8 & Sulit Berpikir Jernih & 0.5 \\
\hline I9 & Merasa Tidak Bahagia & 0.6 \\
\hline $\mathrm{I} 10$ & Sering Menangis & 0.5 \\
\hline I11 & Merasa Sulit Untuk Menikmati Kegiatan Sehari-Hari & 0.4 \\
\hline $\mathrm{I12}$ & Sulit Mengambil Keputusan & 0.4 \\
\hline I13 & Pekerjaan Sehari-Hari Terganggu & 0.6 \\
\hline I14 & Tidak Mampu Melakukan Hal-Hal Yang Bermanfaat Dalam Hidup & 0.6 \\
\hline $\mathrm{I} 15$ & Kehilangan Minat Pada Berbagai Hal & 0.6 \\
\hline I16 & Merasa Tidak Berharga & 0.6 \\
\hline $\mathrm{I} 17$ & Mempunyai Keinginan Untuk Mengakhiri Hidup & 0.7 \\
\hline I18 & Merasa Lelah Sepanjang Waktu & 0.7 \\
\hline I19 & Mengalami Rasa Tidak Enak Diperut & 0.8 \\
\hline $\mathrm{I} 20$ & Mudah Lelah & 0.8 \\
\hline $\mathrm{I} 21$ & Lebih Sering Menggunakan Alkohol/Zat Terlarang Dari Biasanya & 0.7 \\
\hline $\mathrm{I} 22$ & Merasa Seseorang Bermaksud Mencelakai Diri Anda & 0.8 \\
\hline $\mathrm{I} 23$ & Merasa Ada Sesuatu Yang Mengganggu Pikiran Anda & 0.8 \\
\hline $\mathrm{I} 24$ & Mendengar Suara-Suara Yang Tidak Didengar Orang Lain & 0.8 \\
\hline $\mathrm{I} 25$ & Mengalami Mimpi Bencana Atau Seakan Bencana Itu Muncul Kembali & 0.8 \\
\hline
\end{tabular}

\section{Jurnal Ilmiah SISFOTENIKA}




\begin{tabular}{llc}
\hline I26 & $\begin{array}{l}\text { Menghindari Berbagai Kegiatan, Tempat, Orang, Atau Pikiran Yang Mengingatkan Akan } \\
\text { Bencana Tersebut }\end{array}$ & 0.7 \\
\hline I27 & Kurang Tertarik Terhadap Teman-Teman Atau Kegiatan Sehari-Hari & 0.8 \\
\hline I28 & $\begin{array}{l}\text { Merasa Sangat Sedih Apabila Berada Dalam Situasi Yang Mengingatjan Akan Bencana } \\
\text { Tersebut? }\end{array}$ & 0.9 \\
\hline I29 & Sulit Menghayati Dan Mengeluarkan Perasaan & 0.7 \\
\hline
\end{tabular}

Dibawah ini terdapat tabel 3 yang berisikan rules terkait instrumen dan output.

Tabel 3 Rules terkait instrumen dan output

\begin{tabular}{ccc}
\hline Kode & Nama Output & Rule \\
\hline O1 & $\begin{array}{c}\text { Terindikasi Memiliki Masalah Pada } \\
\text { Kesehatan Mental }\end{array}$ & $\begin{array}{c}\text { I4 and I5 and I6 and I8 and I9 and I10 and I11 } \\
\text { and I12 and I13 and I15 and I16 and I17 and I21 } \\
\text { and I22 and I23 and I24 and I25 and I26 and I27 } \\
\text { and I28 and 29 }\end{array}$ \\
\hline O2 & $\begin{array}{c}\text { Tidak Terindikasi Memiliki Masalah } \\
\text { Pada Kesehatan Mental }\end{array}$ & I1 and I2 and I3 and I7 and I18 and 19 and 120 \\
\hline
\end{tabular}

\subsection{Analisis Metode Dempster-Shafer}

Dilakukan pengujian konsultasi, user memilih 3 instrumen yang dirasakan selama 30 hari

1. Sering menderita terakhir yaitu:sakit kepala (I1)

2. Tidak memiliki nafsu makan (I2)

3. Mempunyai keinginan untuk mengakhiri hidup (I17)

\section{Instrumen Pertama:}

Instrumen 1 merupakan instrumen untuk output Tidak Terindikasi $(\mathrm{O} 2)$ dengan nilai belief. Instrumen 1 akan menjadi mass function $\mathrm{m} 1$ dengan menggunakan persamaan (2), maka $\mathrm{m}_{1}(\mathrm{O} 2)=0.8$

$\mathrm{m}_{1}(\theta)=0.2$

\section{Instrumen Kedua:}

Instrumen 2 merupakan instrumen untuk output Tidak Terindikasi(O2) dengan nilai belief. Instrumen 2 akan menjadi mass function $\mathrm{m} 1$ dengan menggunakan persamaan (2), maka $\mathrm{m}_{2}(\mathrm{O} 2)=0.8$ $\mathrm{m}_{2}(\theta)=0.2$

Hasil mass function $\mathrm{m}_{1}$ dan $\mathrm{m}_{2}$ akan dihitung dengan menggunakan rumus kombinasi pada persamaan (3). Untuk mempermudah proses perhitungan dapat digunakan tabel seperti pada tabel 4.

Tabel 4 Perhitungan Iterasi Pertama Dempster-Shafer
\begin{tabular}{lll} 
& $\mathrm{m}_{2}(\mathrm{O} 2) 0.8$ & $\mathrm{~m}_{2}(\theta) 0.2$ \\
\hline $\mathrm{m}_{1}(\mathrm{O} 2) 0.8$ & $(\mathrm{O} 2) 0.64$ & $(\mathrm{O} 2) 0.16$ \\
\hline $\mathrm{m}_{1}(\theta) 0.2$ & $(\mathrm{O} 2) 0.16$ & $(\theta) 0.04$ \\
\hline
\end{tabular}

$$
\begin{aligned}
\mathrm{m}_{3}(\mathrm{O} 2) & =\frac{\sum_{X \cap Y=Z} m_{x}(X) \cdot m_{y}(Y)}{1-K} \\
& =\frac{(O 2)}{1-K}=\frac{0.64+0.16+0.16}{1-0}=0.96 \\
\mathrm{~m}_{3}(\theta) & =1-0.96=0.04
\end{aligned}
$$

\section{Instrumen Ketiga:}


Instrumen 3 merupakan instrumen untuk output Terindikasi(O1) dengan nilai belief. Instrumen 3 akan menjadi mass function $\mathrm{m}_{4}$ dengan menggunakan persamaan (2), maka $\mathrm{m}_{4}(\mathrm{O} 1)=0.7$

$\mathrm{m}_{4}(\theta)=0.3$

Hasil mass function $\mathrm{m}_{3}$ dan $\mathrm{m}_{4}$ akan dihitung dengan menggunakan rumus kombinasi pada persamaan (3). Untuk mempermudah proses perhitungan dapat digunakan tabel seperti pada tabel 5.

Tabel 5 Perhitungan Iterasi kedua Dempster-Shafer
\begin{tabular}{ccc} 
& $\mathrm{m}_{4}(\mathrm{O} 1) 0.7$ & $\mathrm{~m}_{4}(\theta) 0.3$ \\
\hline $\mathrm{m}_{3}(\mathrm{O} 2) 0.96$ & $(\mathrm{~K}) 0.672$ & $(\mathrm{O} 2) 0.288$ \\
\hline $\mathrm{m}_{3}(\theta) 0.04$ & $(\mathrm{O} 1) 0.028$ & $(\theta) 0.012$ \\
\hline
\end{tabular}

$$
\begin{aligned}
\mathrm{m}_{5}(\mathrm{O} 1) & =\frac{\sum_{X \cap Y=Z} m_{x}(X) \cdot m_{y}(Y)}{1-K} \\
& =\frac{(01)}{1-K}=\frac{0.028}{1-0.672}=0.085 \\
\mathrm{~m}_{5}(\mathrm{O} 2) & =\frac{\sum_{X \cap Y=Z} m_{x}(X) \cdot m_{y}(Y)}{1-K} \\
& =\frac{(O 2)}{1-K}=\frac{0.288}{1-0.672}=0.878 \\
\mathrm{~m}_{5}(\theta)= & 1-(0.085+0.878)=0.037
\end{aligned}
$$

Nilai keyakinan yang terbesar terdapat pada $(\mathrm{O} 2)$ yaitu tidak terindikasi memiliki masalah pada kesehatan mental dengan nilai 0.878 sehingga memiliki persentase $87.8 \%$ yang didapat dari 0.878 $\mathrm{x} 100 \%$.

\subsection{Tampilan Sistem}

Desain tampilan sistem pakar deteksi dini kesehatan mental menggunakan metode dempster shafer berbasis web dapat dilihat dari penjelasan berikut

\subsubsection{Halaman Login}

Halaman login merupakan halaman awal user sebelum melakukan konsultasi

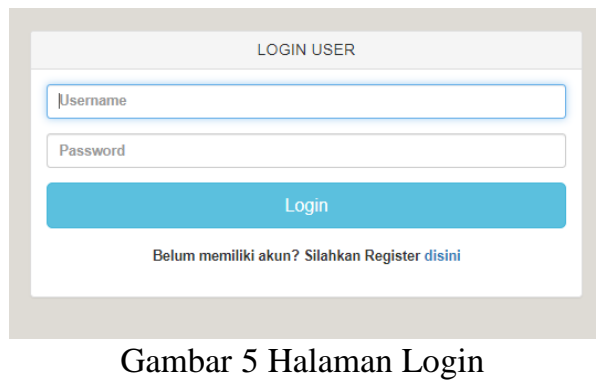

\subsubsection{Halaman Beranda}

Halaman beranda memuat menu yang dapat diakses. 


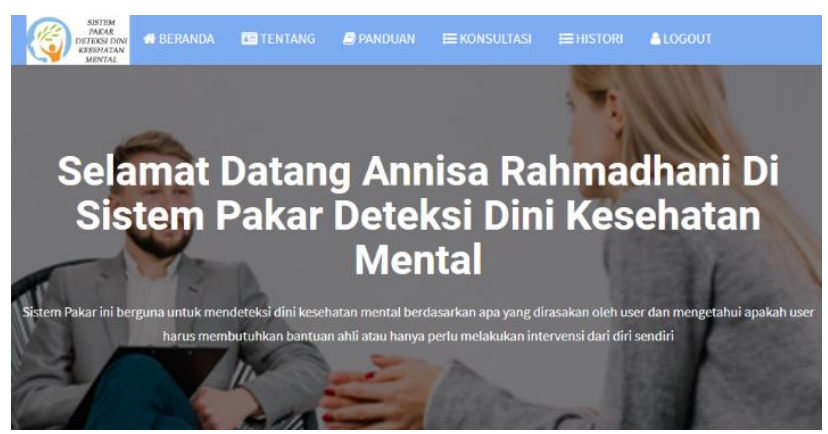

Gambar 6 Halaman Beranda

\subsubsection{Halaman Konsultasi}

Halaman konsultasi menampilkan daftar seluruh instrumen yang dapat dipilih oleh user.
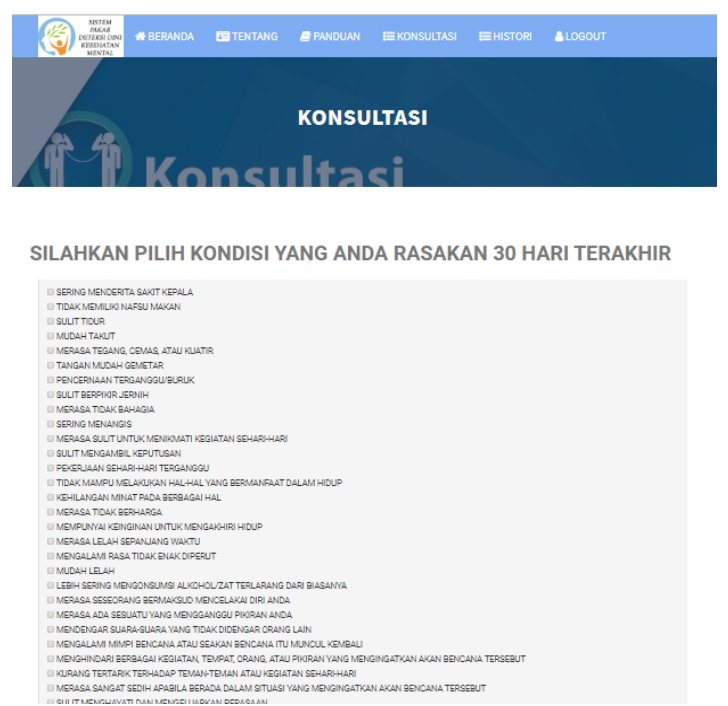

Gambar 7 Halaman Konsultasi

3.3.4 Halaman Hasil Konsultasi

Halaman hasil konsultasi menampilkan hasil deteksi dini user bedasarkan instrumen yang dipilih
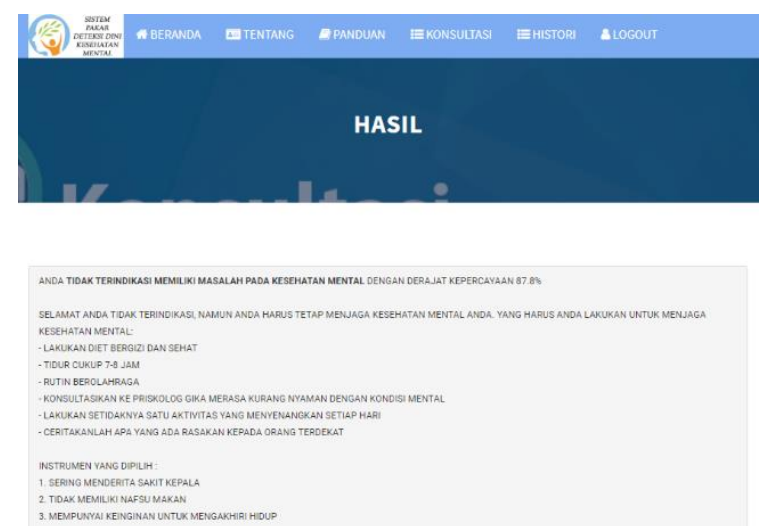

Gambar 8 Halaman Hasil Konsultasi 


\subsubsection{Halaman Histori}

Halaman histori menampilkan data rekap hasil konsultasi yang dilakukan oleh user sebelumnya
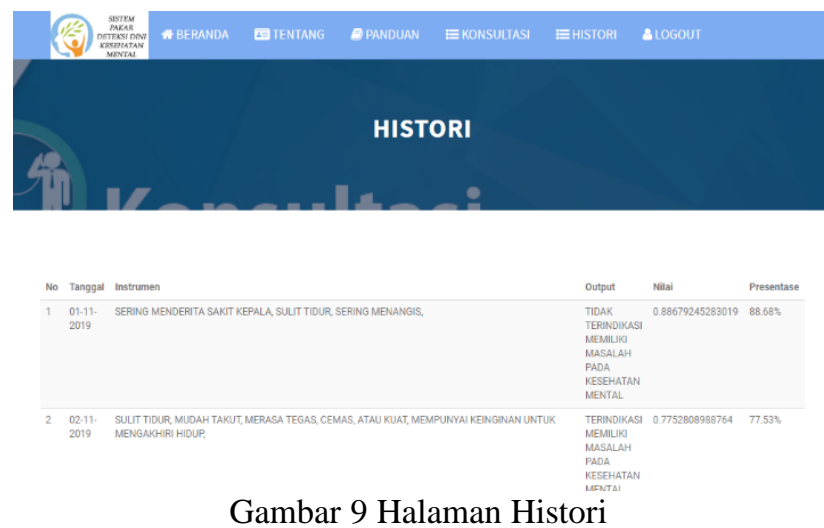

\subsection{Pengujian Sistem}

Berdasarkan hasil pengujian akurasi perbandingan antara hasil sistem dan hasil konsultasi pakar melalui kuesioner yang diberikan kepada psikolog sebanyak 100 data uji dan diambil sampel sebanyak 40 data uji serta pada kolom diagnosa sistem terdapat persentase output konsultasi sehingga didapatkan hasil sebagai berikut:

Tabel 6 Hasil Simulasi Pengujian Akurasi

\begin{tabular}{|c|c|c|c|c|}
\hline No & Indikator & Diagnosa Pakar & Diagnosa Sistem & Hasil \\
\hline 1 & $\mathrm{I} 1, \mathrm{I} 2, \mathrm{I} 17$ & Tidak Terindikasi & Tidak Terindikasi $(87,8 \%)$ & Sesuai \\
\hline 2 & $\mathrm{I} 1, \mathrm{I} 2, \mathrm{I} 14.15$ & Tidak Terindikasi & Tidak Terindikasi (79.34\%) & Sesuai \\
\hline 3 & $\mathrm{I} 3, \mathrm{I} 17, \mathrm{I} 20,126, \mathrm{I} 27$ & Terindikasi & Terindikasi $(94.24 \%)$ & Sesuai \\
\hline 4 & $\mathrm{I} 1, \mathrm{I} 3, \mathrm{I} 10$ & Tidak Terindikasi & Tidak Terindikasi $(88.68 \%)$ & Sesuai \\
\hline 5 & $\mathrm{I} 28, \mathrm{I} 29$ & Terindikasi & Terindikasi $(97 \%)$ & Sesuai \\
\hline 6 & $\mathrm{I} 1, \mathrm{I} 8, \mathrm{I} 9, \mathrm{I} 24$ & Terindikasi & Terindikasi $(82.76 \%)$ & Sesuai \\
\hline 7 & $\mathrm{I} 3, \mathrm{I} 5, \mathrm{I} 17$ & Tidak Terindikasi & Terindikasi (68.75) & Tidak Sesuai \\
\hline 8 & $\mathrm{I} 3, \mathrm{I} 7, \mathrm{I} 10$ & Tidak Terindikasi & Tidak Terindikasi $(83.49 \%)$ & Sesuai \\
\hline 9 & $\mathrm{I} 11, \mathrm{I} 14, \mathrm{I} 26$ & Terindikasi & Terindikasi $(92.8 \%)$ & Sesuai \\
\hline 10 & $\mathrm{I} 22, \mathrm{I} 23$ & Terindikasi & Terindikasi $(96 \%)$ & Sesuai \\
\hline 11 & $\mathrm{I} 19, \mathrm{I} 27, \mathrm{I} 28$ & Terindikasi & Terindikasi $(90.74 \%)$ & Sesuai \\
\hline 12 & $\begin{array}{l}\mathrm{I} 3, \mathrm{I} 4, \mathrm{I} 5, \mathrm{I} 8, \mathrm{I} 9, \mathrm{I} 10, \mathrm{I} 11, \mathrm{I} 14, \\
\mathrm{I} 15\end{array}$ & Terindikasi & Terindikasi $(99.36 \%)$ & Sesuai \\
\hline 13 & I5, I6, I9, I24 & Terindikasi & Terindikasi $(98.08 \%)$ & Sesuai \\
\hline 14 & $\mathrm{I} 16, \mathrm{I} 20, \mathrm{I} 27$ & Terindikasi & Terindikasi $(69.7 \%)$ & Sesuai \\
\hline 15 & $\mathrm{I} 2, \mathrm{I} 7, \mathrm{I} 10$ & Tidak Terindikasi & Tidak Terindikasi $(88.68 \%)$ & Sesuai \\
\hline 16 & $\mathrm{I} 9, \mathrm{I} 11, \mathrm{I} 14, \mathrm{I} 15, \mathrm{I} 24$ & Terindikasi & Terdindikasi $(99.23 \%)$ & Sesuai \\
\hline 17 & $\mathrm{I} 9, \mathrm{I} 18, \mathrm{I} 20$ & Tidak Terindikasi & Tidak Terindikasi $(86.24 \%)$ & Sesuai \\
\hline 18 & $\mathrm{I} 4, \mathrm{I} 8, \mathrm{I} 9, \mathrm{I} 11, \mathrm{I} 12, \mathrm{I} 18$ & Tidak Terindikasi & Terindikasi $(88.93 \%)$ & Tidak Sesuai \\
\hline 19 & $\mathrm{I} 14, \mathrm{I} 18$ & Tidak Terindikasi & Tidak Terindikasi (48.28\%) & Sesuai \\
\hline 20 & $\mathrm{I} 12, \mathrm{I} 13, \mathrm{I} 23$ & Terindikasi & Terindikasi $(95.2 \%)$ & Sesuai \\
\hline 21 & $\mathrm{I} 5, \mathrm{I} 6, \mathrm{I} 7, \mathrm{I} 8, \mathrm{I} 9, \mathrm{I} 10, \mathrm{I} 11, \mathrm{I} 12$ & Terindikasi & Terindikasi $(97.18 \%)$ & Sesuai \\
\hline 22 & $\begin{array}{l}\mathrm{I} 17, \mathrm{I} 18, \mathrm{I} 19, \mathrm{I} 20, \mathrm{I} 21, \mathrm{I} 22, \mathrm{I} 23, \\
\mathrm{I} 24, \mathrm{I} 25\end{array}$ & Terindikasi & Terindikasi $(98.81 \%)$ & Sesuai \\
\hline 23 & $\mathrm{I} 19, \mathrm{I} 26, \mathrm{I} 27$ & Terindikasi & Terindikasi (75.81\%) & Sesuai \\
\hline 24 & $\mathrm{I} 26, \mathrm{I} 27, \mathrm{I} 28$ & Terindikasi & Terindikasi $(99.4 \%)$ & Sesuai \\
\hline 25 & $\mathrm{I} 16, \mathrm{I} 19, \mathrm{I} 22$ & Terindikasi & Terindikasi $(69.7 \%)$ & Sesuai \\
\hline 26 & $\mathrm{I} 17, \mathrm{I} 18, \mathrm{I} 19$ & Tidak Terindikasi & Tidak Terindikasi $(98.8 \%)$ & Sesuai \\
\hline 27 & $\mathrm{I} 20, \mathrm{I} 21$ & Terindikasi & Tidak Terindikasi $(54.55 \%)$ & Tidak Sesuai \\
\hline
\end{tabular}


Annisa Rahmadhani, Fauziah, Andri Aningsih

\begin{tabular}{lllll}
\hline 28 & I3, I5 & Tidak Terindikasi & Tidak Terindikasi (48.28\%) & Sesuai \\
\hline 29 & I6, I7, I29 & Terindikasi & Terindikasi $(57.5 \%)$ & Sesuai \\
\hline 30 & I22, I23, I26 & Terindikasi & Terindikasi (98.8\%) & Sesuai \\
\hline 31 & I3, I12 & Tidak Terindikasi & Tidak Terindikasi (58.33\%) & Sesuai \\
\hline 32 & I9, I10, I11, I12, I17, I22 & Terindikasi & Terindikasi (99.57\%) & Sesuai \\
\hline 33 & I25, I26, I28 & Terindikasi & Terindikasi (99.4\%) & Sesuai \\
\hline 34 & I3, I10, I19, I20 & Tidak Terindikasi & Tidak Terindikasi (97.63\%) & Sesuai \\
\hline 35 & I3, I4 & Terindikasi & Terindikasi (53.85\%) & Sesuai \\
\hline 36 & I21, I23, I29 & Terindikasi & Terdindikasi (998.2\%) & Sesuai \\
\hline 37 & I7, I8, I19 & Tidak Terindikasi & Tidak Terindikasi (88.68\%) & Sesuai \\
\hline 38 & I1, I2, I3, I4, I5, I6, I7, I8, I9 & Terindikasi & Tidak Terindikasi (86.92\%) & Tidak Sesuai \\
\hline 39 & I1, I7, I9 & Tidak Terindikasi & Tidak Terindikasi (86.24\%) & Sesuai \\
\hline 40 & I7, I14, I17, I18, I27, I28, I29 & Terindikasi & Terindikasi (99.21\%) & Sesuai \\
\hline
\end{tabular}

Dari 20 data sampel pengujian akurasi perbandingan antara hasil sistem dan hasil pakar, maka didapatkan:

$\frac{\text { Banyak data uji sampel yang sesuai }}{\text { Banyak data uji sampel }} \times 100 \%$.

$\frac{36}{40} \times 100 \%=90 \%$

Sedangkan berdasarkan hasil 100 data pengujian akurasi perbandingan antara hasil sistem dan hasil pakar pada tabel 6 didapatkan:

$$
\begin{aligned}
& \frac{\text { Banyak data uji yang sesuai }}{\text { Banyak data uji }} \times 100 \% \\
& \frac{94}{100} \times 100 \%=94 \%
\end{aligned}
$$

Dari perhitungan persentase tingkat keakurasian sistem yang didapatkan dari 100 data uji perbandingan hasil sistem dan hasil pakar mengalami kenaikan persentase dibandingkan dari tingkat keakurasian sistem yang didapatkan dari 40 data uji sampel dan didapatkan sebanyak 94 data yang sesuai dari 100 data uji dan 6 data yang tidak sesuai dikarenakan instrumen yang dipilih masih sedikit dan kurang spesifik, sehingga dapat dikatakan bahwa sistem pakar deteksi dini kesehatan mental ini memiliki tingkat keberhasilan sebesar $94 \%$ yang berarti sistem sudah dapat berjalan dengan baik.

\subsection{Pengujian Usability}

Pada pengujian usability sistem menggunakan 9 pertanyaan dan dilakukan penyebaran kuesioner yang diberikan pada 31 koresponden, selanjutnya dilakukan rekap nilai pada setiap pertanyaan terhadap hasil kuesioner yang telah disebar. Berdasarkan persentase hasil usability testing dalam setiap pertanyaan memiliki skala 1-5, pada skala 1 (sangat tidak mudah), 2 (tidak mudah), 3 (cukup mudah), 4 (mudah), 5 (sangat mudah). Selanjutnya untuk mendapatkan nilai total dari seluruh aspek digunakan persamaan (6).

Jumlah Nilai dari Setiap Pertanyaan

Jumlah Pertanyaan

$\frac{3.87+3.96+3.96+4+3.93+4+3.90+4.1+4.1}{9}=3.95$

maka diperoleh rekap nilai usability yang terlihat pada tabel 7 . 
Tabel 7 Hasil Pengujian Usability

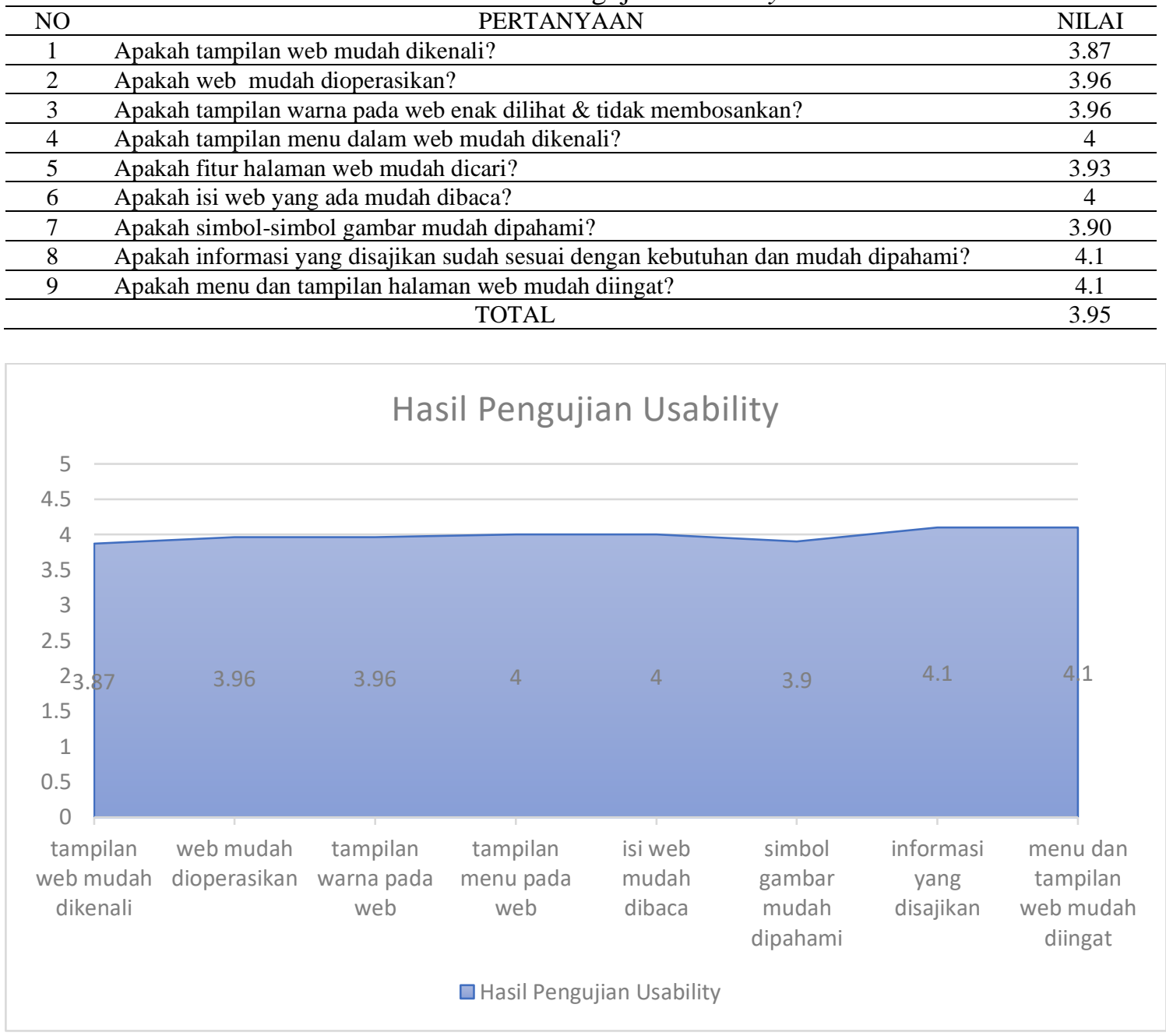

Hasil rekap nilai pengujian usability sistem menunjukkan keseluruhan pertanyaan memiliki nilai usability 3.95 dari nilai total range 5, sehingga dapat dikatakan bahwa sistem informasi yang disajikan kepada pengguna sudah baik dan mudah digunakan oleh semua kalangan.

\section{KESIMPULAN}

Dari hasil penelitian tentang sistem pakar deteksi dini kesehatan mental berbasis web ini, dapat diambil kesimpulan yaitu sistem ini memiliki keunggulan dibandingkan penelitian sebelumnya dimana sistem pada sisi pengguna memiliki data rekap histori hasil konsultasi yang dapat digunakan sebagai perkembangan hasil konsultasi terkait kesehatan mental pengguna. Selain itu, berdasarkan pengujian akurasi sistem perbandingan antara hasil sistem dan hasil pakar, sistem memiliki tingkat keberhasilan sebesar $94 \%$ dan pengujian usability yang didapatkan dari kuesioner memiliki nilai usability sebanyak 3.95 dari total nilai 5 yang artinya sistem informasi yang disajikan kepada pengguna cukup baik serta sistem pakar ini dinilai layak untuk direkomendasikan sebagai deteksi dini kesehatan mental dengan menggunakan metode dempstershafer. Namun, sistem pakar ini tidak dapat dijadikan sebagai final decision. Konsultasi resmi dengan Pakar/Psikolog tetap menjadi faktor utama dalam penyelesaian masalah dalam kesehatan mental.

\section{Jurnal Ilmiah SISFOTENIKA}




\section{SARAN}

Diharapkan pada penelitian selanjutnya dapat mengembangkan sistem dengan mengintegrasikan sistem kepada psikolog yang ada di lokasi sekitar pengguna melakukan konsultasi sehingga lebih memudahkan pengguna dalam melakukan penanganan lanjut serta memberikan solusi yang lebih rinci terkait penanganan masalah pada kesehatan mental. Selain itu, diharapkan sistem dapat dikembangkan dari sisi platform dari web menjadi berbasis android/ios agar semakin memudahkan pengguna untuk mengakses sistem.

\section{DAFTAR PUSTAKA}

[1] Dumilah, A., Misnaniarti., Marisa, R, 2018. Analisis Situasi Kesehatan Mental Pada Masyarakat Di Indonesia Dan Strategi Penanggulangannya. Jurnal Ilmu Kesehatan Masyarakat, No.1, Vol.9, 1-10.

[2] Dina, H., Fitri, B, 2018. Sistem Pakar untuk Mendiagnosis Gangguan Anak Menggunakan Metode Dempster Shafer. J-COSINE, No.2, Vol.2, 71-79.

[3] Doddy, T.Y., Abdul, F., Sunardi, 2019. Implementasi Sistem Pakar Diagnosa Gangguan Kepribadian Menggunakan Metode Dempster Shafer. Jurnal Sistem Informasi Bisnis, No.1, Vol.9, 25-31.

[4] Khairunnisa, N, Huzaeni, Akmalul, F, 2018, Sistem Pakar Gangguan kepribadian (Personality Disorders) Menggunakan Metode Dempster Shafer Berbasis Web, Proceeding Seminar Nasional Politeknik negeri Lhokseumawe, Medan, semptember 2018.

[5] Reza, S., Cucu, S., Syamsul, B, 2018. Implementasi Metode Dempster Shafer pada Sistem Pakar Diagnosa Infeksi Penyakit Tropik Berbasis Web. Jurnal Coding, No.3, Vol.6, 97106.

[6] Aprilia, I.F., Tedy, R., Syamsul, B, 2018. Aplikasi Sistem Pakar Diagnosa Penyakit pada Anak Dengan Inference Forward Menerapkan Metode Dempster Shafer Berbasis Web. Jurnal Coding, No.3, Vol.6, 25-35.

[7] Doddy, T.Y., Abdul, F., Sunardi, 2019. Comparative Analysis of Dempster Shafer Method and Certainty Factor Method On Personality Disorders Expert System. Scientific Journal of Informatics, No.1, Vol.6, 12-22.

[8] Erwin, P, 2018. Comparative Analysis of Dempster Shafer Method and Certainty Factor Method For Diagnose Stroke Diseases. International Journal of Artificial Intelegence Research, No.1, Vol.2, 37-41.

[9] David, 2016. Sistem Pakar Diagnosa Penyakit Gangguan Jiwa dengan Dempster Shafer. Konferensi Nasional Sistem Informasi (KNSI) 2016. pp.197-203. 